\title{
A AUTO-AVALIAÇÃO COMO INSTRUMENTO DE CONSCIENTIZAÇÃO DE ALUNOS DE UM CURSO DE ESPECIALIZAÇÃO LATO SENSU
}

\section{SELF-ASSESSMENT AS A TOOL FOR STUDENTS'AWARENESS OF A LATO SENSU SPECIALIZATION COURSE}

Robson Carlos da SILVA*

Resumo: O presente artigo foi elaborado com base em estudo desenvolvido a partir de uma experiência efetivada por meio de uma prática de auto-avaliação realizada com alunos da disciplina Fundamentos da Educação, no Curso de Especialização em Docência Superior, da FAESPI (Faculdade de Ensino Superior do Piauí), instituição localizada em Teresina - PI. O estudo constou da análise do discurso de uma amostra de textos auto-avaliados produzidos por alunos do curso, selecionados e organizados em três blocos, de acordo com a participação dos alunos nas aulas e nas discussões, em um processo que teve início no primeiro dia aula, preparando-se os alunos e expondo de forma clara o objetivo que se pretendia alcançar. Fundamentado teoricamente por autores que têm uma vasta produção no campo da avaliação educacional (BLOOM, 1983; HOFFMANN, 1998; SANT'ANNA, 1995) e apresentando um sucinto passeio pela teoria da Análise do Discurso (LUKE, 2003; ORLANDI, 2005), o estudo remete ao entendimento de que uma prática de auto-avaliação, desde que orientada de forma clara em seus objetivos e finalidades, pode contribuir significativamente na aprendizagem e no crescimento pessoal dos alunos.

Palavras-Chave: Auto-avaliação. Avaliação participativa. Análise do discurso.

* Professor da Universidade Estadual do Piauí (UESPI); Mestre em Educação pela Universidade Federal do Piauí (UFPI); Professor na Faculdade Certo (FACE). E-mail: bobraizes@hotmail.com 


\begin{abstract}
The present article was based on the study about self-assessment carried out with students of the discipline of Basics of Education, at the Specialization Course in Higher Education from FAESPI (College of Higher Education in Piauí), in Teresina, PI. The study included the discourse analysis of a sample of texts produced and self-assessed by the course attendants. The texts were selected and organized into three blocks according to the participation in class and in the discussions in a process that started on the first day of class in order to prepare the students and explain in a clear way the purpose of the self-assessment activity. The study was based on authors that have a vast production in the area of educational assessment (BLOOM, 1983; HOFFMANN, 1998; SANT'ANNA, 1995) and it presents a succinct review of Discourse Analysis (LUKE, 2003 ORLANDI, 2005), the study refers to an understanding of a selfassessment practice once it is guided in a clear way concerning its aims and goals. This way self-assessment can contribute meaningfully to the learning and personal growth of students.
\end{abstract}

Keywords: Self-assessment. Participatory assessment. Discourse analysis.

\title{
INTRODUÇÃO
}

Neste artigo, nossa proposta é relatar uma prática de autoavaliação realizada com uma turma de alunos do Curso de Especialização em Docência Superior, da Faculdade de Ensino Superior do Piauí (FAESPI), na disciplina Fundamentos da Educação, ministrada no período de 26/02 a 23/04 do corrente ano, durante oito encontros, num total de 60 (sessenta) horas de aula. As aulas foram realizadas quinzenalmente, aos sábados e domingos. A turma foi composta por 34 alunos com formação acadêmica em diversos campos do conhecimento, tais como Pedagogia, Letras, Turismo, Enfermagem, Nutrição, Física, Matemática, História e Geografia.

A prática da auto-avaliação surgiu de uma proposta lançada no 
primeiro dia de aula. Foi solicitado aos alunos que, durante o andamento da disciplina, refletissem sobre seu desempenho nas discussões, atividades propostas e estudos realizados em grupos ou individualmente, bem como nas atividades avaliativas, e que construíssem uma produção escrita a partir da análise desse desempenho, destacando seus aspectos positivos e negativos, as dificuldades encontradas, o posicionamento do professor na condução das discussões. Além disso, numa escala de $\mathrm{O}$ (zero) a 5 (cinco) pontos, deveriam atribuir-se uma nota, a qual seria adicionada a outra, atribuída pelo professor, também com valor de $\mathrm{O}$ (zero) a 5 (cinco) pontos, concretizando-se, assim, na terceira nota da disciplina.

Com esse procedimento, pretendíamos alcançar dois objetivos: o primeiro seria cercar o processo de auto-avaliação do maior grau de legitimidade possível, visto que o aluno não poderia atribuir para si uma nota de forma aleatória ou sem uma reflexão sincera, visando apenas a uma nota alta, já que esta ainda passaria pela análise do professor e de uma complementação a partir de suas análises sobre o desempenho de cada aluno. O segundo objetivo seria demonstrar que, mesmo ainda sofrendo a desconfiança e o descrédito por parte de muitos professores, alunos e estudiosos, a auto-avaliação pode ser um importante instrumento de reflexão sobre a prática educativa, contribuindo para uma maior conscientização crítica e para a autonomia intelectual das pessoas.

\section{O PROCESSO DE AVALIAÇÃO NO CONTEXTO EDUCA- CIONAL}

$\mathrm{Na}$ educação, o ato de avaliar constitui-se num processo de encaminhamento para detectar o estado em que se encontram as pessoas e os demais elementos envolvidos no cotidiano dos espaços educacionais, no sentido de estabelecer determinada comparação entre o que se conseguiu realizar e o que se objetivava atingir, para o estabelecimento de juízos de valor.

Segundo Sant'Anna (1995), a avaliação permite ao professor a oportunidade de verificar se as atividades e os recursos que utiliza estão possibilitando ao aluno o alcance dos objetivos propostos na disciplina, inclusive desenvolvendo com todos os envolvidos no processo uma ação cooperativa, coletiva, crítica e responsável. 
A avaliação é considerada, atualmente, o processo que possibilita uma maior compreensão sobre a dinâmica escolar, diagnosticando a situação da realidade analisada e possibilitando modificações nessa realidade a partir de possíveis necessidades identificadas, notadamente a partir de 1976, quando a Fundação e Coordenação de Aperfeiçoamento do Ensino Superior (CAPES) institucionalizou o processo de auto-avaliação em programas de Pós-graduação realizados no Brasil (MASETTO, 2004).

Na concepção de Hoffmann (1998), a avaliação configura-se em uma ação pedagógica mediadora que, partindo da reflexão sobre o saber elaborado pelos alunos, encaminha ações carregadas de intenções e reveladoras de novas posturas dos professores e demais sujeitos do processo educacional escolar.

Partindo do pensamento de Bloom (1983), podemos afirmar que a avaliação da aprendizagem pode ser classificada em três modalidades: a) diagnóstica - feita no início ou durante o processo de aprendizagem do aluno, serve para identificar as dificuldades apresentadas, por meio do emprego de instrumentos como pré-teste, teste padronizado de rendimento e fichas de observação, e tem como objetivo definir a presença ou ausência de pré-requisitos determinados; b) formativa - realizada durante o processo educativo e com a utilização de instrumentos planejados que dependem dos objetivos propostos, visa a informar sobre o desenvolvimento dos alunos nas atividades de aprendizagem e localizar possíveis deficiências do ensino; c) classificatória - desenvolvida por meio de exames, provas e testes finais realizados sempre no final de determinado período (bimestral, semestral, anual), busca classificar os alunos segundo os níveis de aproveitamento por eles apresentados.

Segundo Ferreira, a respeito da elaboração de um instrumento avaliativo, "[...] há uma tendência à insatisfação quanto aos aspectos técnicos de elaboração do instrumento [...]". (2002, p. 81), o que contribui para o entendimento de que o professor deve ser mais competente e rigoroso na elaboração desses instrumentos, permitindo que os alunos demonstrem sua criatividade e expressem suas próprias idéias. 


\section{FACES DA AUTO-AVALIAÇÃO}

A auto-avaliação é um instrumento concebido para possibilitar que os alunos analisem seu próprio desempenho, destacando pontos positivos e negativos, necessidades ou avanços, em busca do alcance de seus propósitos, os quais consistiriam, mais imediatamente, em uma aprendizagem significativa de determinado conhecimento, no domínio de determinadas competências e em sua conseqüente aprovação no processo.

No plano institucional, foi a partir da década de 80 que começaram a se difundir pelo Brasil os programas de auto-avaliação, coordenados pela CAPES, nos cursos de Pós-graduação das Universidades. Como destaca Masetto (2004), a primeira experiência, nesse sentido, data do ano de 1983, no programa de Educação e Currículo, da Pontifícia Universidade Católica de São Paulo (PUC). Entre os anos de 1983 e 1985, o Conselho Nacional de Desenvolvimento Científico e Tecnológico (CNPq) financia e acompanha o processo de auto-avaliação de todos os programas de Mestrado e Doutorado da PUC de São Paulo. No período entre 1987 e 1989, a Universidade Federal de Minas Gerais (UFMG) instala seu projeto de auto-avaliação, traçando o perfil de seus cursos de Mestrado e Doutorado e encaminhando políticas de planejamento. Em 1989 é a vez da Universidade Federal do Ceará (UFC) concretizar o seu projeto de auto-avaliação e, já na década de 90, mais precisamente entre os anos de 1994 e 1995, a Universidade Estadual de Campinas (UNICAMP) formula trabalhos sobre o processo de avaliação institucional, focalizando a questão da auto-avaliação.

Desde o dia $1^{\circ}$ de setembro de 1994 , o Ministério da Educação (MEC) adotou o processo nacional de Avaliação Institucional da Educação Superior, atendendo a determinações do Sistema Nacional de Avaliação da Educação Superior (Sinaes). (INEP/MEC, 2004). O processo centra-se na idéia de institucionalização de um sistema de avaliação que integra três modalidades de instrumentos avaliativos, cada qual aplicado em um momento particular, porém de forma integrada. São eles: Avaliação das Instituições de Educação Superior (Avalies), Avaliação dos Cursos de Graduação (ACG) e Avaliação do Desempenho dos Estudantes (Enade).

O momento de Avaliação dos Cursos de Graduação é realizado por meio da avaliação efetivada por visitas in loco, por comissões 
externas, na própria instituição. O momento de Avaliação do Desempenho dos Estudantes acontece por meio da realização do Enade, exame aplicado aos alunos que estão cursando o primeiro e o último ano do curso avaliado, os quais são escolhidos por procedimentos amostrais, de acordo com a referida área de conhecimento, que é previamente definida pelo Conaes (Comissão Nacional de Avaliação de Educação Superior).

Porém, o momento mais importante para o contexto enfocado neste artigo diz respeito à Avaliação das Instituições de Educação Superior (Avalies), a Avaliação Interna ou Auto-Avaliação. As orientações do Sinaes determinam que cada Instituição componha sua Comissão Própria de Avaliação (CPA), que coordenará todo o processo de desenvolvimento da auto-avaliação. A proposta está assentada na idéia de que, a partir do conhecimento da própria realidade e dos significados do conjunto de suas atividades, cada instituição poderá desenvolver ações mais pertinentes no sentido de melhorar sua qualidade educativa, alcançar resultados positivos e, conseqüentemente, atingir melhores significados em relação a sua relevância social.

Sem a pretensão de esgotar a questão, é interessante ressaltar a crítica que Masetto (2004) faz sobre a forma com que a CAPES conduz seu processo de avaliação a respeito dos projetos institucionais que, centrados num privilégio excessivo de coleta de dados e informações quantitativas, acabaram por levar a uma prática que se esgotou, muitas vezes, no simples preenchimento de exaustivos relatórios, quase não sobrando tempo para as análises e reflexões críticas.

Como temos enfatizado, a auto-avaliação constitui-se numa autocrítica efetivada pelos alunos quanto ao seu próprio desempenho, devendo centrar-se numa reflexão fiel em que conste a contextualização do curso ou da disciplina, a sua evolução, dificuldades, avanços, condições de produção, além da condução do trabalho docente nesse processo, devendo servir para diagnosticar o momento analisado, estimular a participação dos alunos no processo avaliativo e a condução de novos sentidos para a prática docente.

\section{INQUIETAÇÕES QUE ORIENTARAM A PESQUISA}

A inquietação que motivou a experiência ora relatada surgiu de nossa busca para entender como a avaliação do rendimento dos 
alunos de um Curso de Especialização poderia fornecer maiores referências e indicativos da sua aprendizagem, notadamente no tocante ao seu próprio envolvimento no processo avaliativo, uma vez que, em cursos de tal natureza, os alunos devem apresentar um grau de conscientização e de amadurecimento bastante significativo. Buscamos, ainda, o entendimento do modo como os alunos estão construindo o seu conhecimento, apontando possíveis dificuldades e revelando os conhecimentos que adquiriram de forma significativa.

A auto-avaliação é um instrumento muito empregado em nossas aulas em cursos de graduação ${ }^{1}$, sempre com o predomínio de bons resultados, mas que apresenta alguma resistência por parte de alunos e mesmo de professores.

Quando comentávamos o emprego da auto-avaliação, era notória a desconfiança que os professores demonstravam na capacidade dos alunos em realizar uma auto-avaliação, mais precisamente na capacidade dos alunos em agirem de forma "justa" em seu próprio juízo, de não se atribuir uma nota ou conceito de que não fossem merecedores. Ou seja, para muitos professores os alunos tendem a atribuir ao próprio desempenho, por meio da auto-avaliação, sempre uma nota elevada, longe da capacidade demonstrada durante as aulas.

Assim, reiterando nossa confiança na fidedignidade da autoavaliação, resolvemos propor aos alunos do Curso de Especialização que produzissem um texto argumentativo, no qual constaria a autoavaliação de seu desempenho na disciplina por nós ministrada. Para conseguirmos atingir plenamente os objetivos da construção teórica desse texto auto-avaliativo, enfatizamos a questão da construção textual enquanto uma ação de significativa importância na circulação e difusão dos discursos.

Nesse sentido, a partir do entendimento de que os textos devem ser considerados como "[...] ações sociais [...] instâncias significativas e coerentes do uso falado e escrito da linguagem" (LUKE, 2003, p. 103), e de que sejam eles orais, escritos ou visuais, são construídos com o interesse de produzir algo ou algum efeito nas instituições e situações (fenômenos) sociais, materializando-se nas práticas dos sujeitos, tomamos os textos produzidos como significantes e representativos

\footnotetext{
${ }^{1}$ Desde nossas primeiras experiências acadêmicas, nos cursos de período de férias promovidos pela UESPI, passando pelas experiências como professor substituto da UFPI, assim como em nossas experiências na FAESPI (Faculdade de Ensino Superior do Piauí), nos utilizamos da prática da auto-avaliação dos alunos, sempre com a predominância de bons resultados.
} 
na constituição da avaliação dos alunos do Curso de Especialização destacado neste artigo.

\section{ANÁLISE DOS DISCURSOS DE TEXTOS AUTO-AVALIA- TIVOS}

Centrados no estudo de aportes teóricos da Análise do Discurso, concebemos uma forma de analisar os textos em busca "[...] do real sentido em sua materialidade lingüística e histórica [...]" (ORLANDI, 2005, p.59), a partir da idéia de que todo discurso é um processo em curso, uma prática discursiva, especificada por sua característica simbólica. Assim, selecionamos alguns textos auto-avaliativos produzidos pelos alunos sujeitos deste estudo, tendo como critério aqueles que demonstraram maior coerência entre sua prática (desempenho participativo nas discussões fomentadas; compromisso em assistir às aulas, realização das atividades propostas pelo professor) e o seu discurso textual, ou seja, a análise e conceito atribuídos ao próprio desenvolvimento.

As contribuições que a Análise de Discurso pode trazer para a prática da pesquisa em Educação são bastante relevantes, notadamente na questão das análises dos dados levantados em estudos de natureza qualitativa, ponto angustiante para muitos pesquisadores iniciantes, os quais reclamam da falta de aportes teóricos que possam melhor conduzir esse aspecto da pesquisa. Não pretendemos, no presente artigo, efetivar um aprofundado estudo sobre tais contribuições, mas apenas pontuar aspectos relevantes da teoria da Análise de Discurso, que possam contribuir com maior clareza para o entendimento de alguns discursos dos sujeitos do estudo.

Uma primeira contribuição que percebemos diz respeito à forma com que devemos nos posicionar diante de determinados discursos para interpretarmos seus significados, visto que, segundo Cardoso (2005, p. 51), "Palavras, expressões, proposições mudam de sentido segundo posições sustentadas por aqueles que as empregam, o que significa que elas tomam seu sentido em referência a essas posições, isto é, em referência às formações ideológicas nas quais essas posições se inscrevem".

Portanto, a partir de uma postura de analista de discurso, devemos atentar mais precisamente e de forma mais apurada para os 
contextos em que os sujeitos emitem ou constroem seus discursos, não esquecendo de relacionar constantemente o dizer desses sujeitos e suas práticas concretas. (ORLANDI, 2001).

Finalmente, para os propósitos deste texto, é importante destacar que todo discurso é construído segundo uma finalidade; é uma forma de ação sobre o "outro" e, nesse sentido, é interativo, contextualizado e assumido por um determinado sujeito (MAINGUENEAU, 2001).

Passaremos agora à transcrição e análise dos discursos que compõem as auto-avaliações produzidas pelos alunos ${ }^{2}$. Optamos por dividir as auto-avaliações em três blocos distintos. O primeiro bloco é constituído pelas produções dos alunos que tiveram uma participação entre fraca e regular, deixando muito a desejar nas discussões e apresentando muitas faltas aos encontros. No segundo bloco trabalhamos com as análises dos alunos que tiveram boa freqüência nos encontros, porém com uma participação somente regular. No terceiro e último bloco destacamos as produções dos alunos que, além de freqüentarem assiduamente às aulas, demonstraram um excelente nível de participação, integração e domínio de conteúdo.

Por conseguinte, neste primeiro bloco estão os alunos que pouca ou quase nenhuma participação tiveram nas discussões, além de apresentarem pouco interesse nas reflexões levantadas, demonstrando, inclusive, falta de concentração e dispersão constante, com conversas paralelas e saídas constantes da sala de aula. Vejamos suas falas:

A minha participação na disciplina foi muito boa, pois contribuí nos debates, discussões e realização nos trabalhos individuais e em grupo. Sempre participei e procurei participar nas discussões e trocar idéias. Isto foi muito importante no enriquecimento profissional e pessoal e sobre a visão do que é educação. Estive ausente em um final de semana, pois fui acidentado na sexta-feira à noite, véspera do fim de semana de aula. Mesmo assim, fiz todos os trabalhos individuais e em grupo. Minha nota: 04. (Alan)

Auto-avaliação é uma tarefa difícil, pois, a meu ver, é um confronto entre a perspectiva do novo e seus conhecimentos. Nesta disciplina, creio que o objetivo foi alcançado. Consegui criar conceitos sobre educação e convívio com as pessoas de graduações diferentes. Minha

${ }^{2}$ Todos os alunos que participaram deste estudo serão identificados por nomes fictícios, a fim de se resguardar suas identidades e preservar sua privacidade.

Olhar de professor, Ponta Grossa, 10(2): 101-115, 2007.

Disponível em < http:// www.uepg.br/olhardeprofessor 
participação nos debates não foi tão boa como eu pretendia. Mas tentei intervir nos momentos em que me senti seguro da minha contribuição. Não colocarei nota, deixo a seu critério, mas acredito que minha participação foi boa, uma vez que tive um bom professor que me deixou à vontade dentro de minhas dúvidas e incertezas. (Álvaro).

Percebe-se uma tentativa dos alunos em justificar suas ausências, uma atitude de reconhecimento da não participação nas aulas, bem como uma confusão em explicitar aspectos que foram relevantes nas discussões. Ou seja, eles não conseguem formar claramente uma idéia das propostas e objetivos da disciplina, nem dizer se os objetivos foram atingidos.

$\mathrm{Na}$ análise dos discursos desse primeiro bloco, nos reportamos ao que defende Orlandi, quando afirma: "O sujeito, diríamos, está para o discurso assim como o autor está para o texto." (2005, p.73). Ao mesmo tempo, considerando que o produto de uma análise é a compreensão dos processos de produção de sentidos e da posição que os sujeitos assumem em seus discursos, podemos perceber que a dispersão de idéias e de sentidos presentes nos discursos do referido bloco significa a falta de uma real capacidade crítica e analítica dos sujeitos que os produziram, em sua auto-avaliação. Assim mesmo há uma tendência à atribuição de um conceito, de certa forma, elevado, nos conduzindo a afirmar que quanto mais os sujeitos se integram em determinado processo, notadamente em um nível acadêmico, mais tendem a ser conscientes de seu papel e da clareza de suas potencialidades.

Seguiremos agora com o segundo bloco de discursos, composto das análises dos alunos que tiveram boa freqüência nos encontros, porém com uma participação somente regular:

Embasada nas leituras, reflexões e discussões em sala de aula, a disciplina contribuiu substancialmente para o meu crescimento pessoal e profissional. Tive compromisso com a disciplina e com os trabalhos, entregando-os na data prevista. O percentual de aproveitamento, a partir dos aspectos avaliados, foi entre 90 e 95\%. Numa escala de 0 a 5, fazendo uma auto-crítica, sou passiva de uma nota 4.0, pois apesar de ter participado das discussões, senti que alguns colegas têm mais afinidade com a disciplina, se saíram muito bem nas discussões, com fundamentação teórica profunda e 
diversificada. (Bela)

[...] minha freqüência tem sido assídua e atuante, não no sentido participativo, pois sou um pouco introvertida, mas mesmo assim tentei me empenhar na atenção dada a disciplina, em conjunto com a participação ativa nos trabalhos realizados. A leitura também foi fundamental para aumento do meu conhecimento, embora não a tenha expressado claramente em fala por motivo já citado. Sendo assim, adquiri conhecimento a mais, com certeza, mesmo não merecendo mais que colegas que desde o inicio participaram. 4,0 pontos. (Bárbara).

No decorrer da disciplina Fundamentos da Educação, consegui esclarecer alguns pontos que ainda não estavam de certa forma entendidos na minha concepção como Pedagoga. Mesmo no momento em que eu mais ouvi do que falei, consegui internalizar e aprofundar bastante meus conhecimentos teóricos. Eu tenho certeza que a minha participação nos debates deixou a desejar, em alguns momentos. Mas é uma característica minha, eu sou mais de ouvir e escrever e neste sentido cumpri o meu papel. Estive presente em todas as aulas, entreguei todos os trabalhos no prazo determinado e pelos motivos citados acima eu mereço a nota 4 (quatro). (Brenda).

Os textos que constituem o segundo bloco são de alunos que demonstram um maior compromisso com a disciplina, embora ainda deixassem a desejar na freqüência e apresentassem um comportamento predominantemente tímido, visto que, ao se manifestarem, demonstravam uma boa capacidade de crítica e entendimento dos questionamentos. Podemos afirmar que os alunos cujos textos compõem esse bloco se encontram em um nível entre bom e ótimo.

Diferentemente do bloco anterior, aqui podemos perceber uma visão crítica dos cursistas, assentada numa postura mais humilde e, acima de tudo, já bastante consciente de seu desempenho, evitando subterfúgios e assumindo seus próprios pontos fracos. Assim, em sua auto-avaliação, eles evitaram também a atribuição da nota máxima.

Podemos identificar, a partir das análises dos textos do segundo bloco, a característica da auto-avaliação destacada por Sant'Anna (1995) - a criação de condições para o aluno pensar sobre si mesmo, preparando-se para uma aprendizagem verdadeiramente significativa -, funcionando positivamente no discurso dos alunos. 
Vamos, por fim, às análises dos discursos do terceiro e último bloco, constituído por alunos que, além de freqüentarem assiduamente às aulas, demonstraram um excelente nível de participação, integração e domínio de conteúdo:

Vi a matéria como uma experiência gratificante, onde houve um feedback favorável, pois a maneira que a matéria foi repassada, principalmente nas discussões onde a heterogeneidade dos participantes foi fundamental, traz uma experiência impar. Foi um privilégio ter a oportunidade de participar dessas discussões colocando minhas críticas e recebendo a dos colegas em troca. Mediante o exposto que faço, considero minha participação como proveitosa no processo ensinar-aprender, por isso me daria nota 5,0. (Carlos)

Auto-avaliar é uma tarefa difícil, requer consciência e discernimento. É uma tarefa árdua, por isso sinto-me na responsabilidade de ser franco e assim o serei. Foi uma tarefa riquíssima discutir a educação, objeto de nosso estudo nesta disciplina, porque ela nos deu mais abertura para mudanças de postura na sala de aula. Participei das discussões quando necessário, embora achando que poderia ter feito mais, e fiz muita leitura em casa do que discutimos. Percebo que mereço a nota 4,0 (quatro). (César)

Fazer uma avaliação de uma outra pessoa já é muito difícil; uma auto-avaliação é mais complicada ainda, pois para fazer nossa própria crítica precisamos ser muito conscientes e honestos. Diante de uma turma heterogênea, onde tem pessoas de várias graduações além de pensamentos variados, percebo que ainda preciso ler e conhecer mais para fundamentar minhas teorias e correntes filosóficas e sociológicas. Apesar dessas dificuldades eu me avalio como uma pessoa assídua, compromissada com o curso. Eu me coloco com uma nota 5, pois diante do que foi proposto com o trabalho e participação, entreguei no tempo previsto e as minhas colocações diante os assuntos foram coerentes. (Camila.)

No terceiro bloco foram incluídos os discursos dos alunos que tiveram uma participação efetiva nas aulas, nas discussões e alcançaram o conceito pleno em nossa avaliação. Foram os alunos que contribuíram significativamente para o desenvolvimento do processo de reflexão proposto para a disciplina, tornando possível 
a condução da disciplina pautada sempre na discussão cooperativa, na participação e na concretização de espaços de livre manifestação de idéias. Todos os alunos cujos discursos compõem esse bloco demonstraram excelente capacidade crítica, objetividade e clareza em suas colocações, domínio de conteúdo e, notadamente, originalidade e criatividade bastante aflorada.

Percebe-se, em seus discursos, uma postura de autoridade diante das análises auto-avaliativas e da reflexão que fazem sobre sua prática, enquanto alunos de um curso de pós-graduação, fruto da clareza que possuem de seu desempenho. Mesmo quando se atribuem um conceito pleno (5,0 pontos), o fazem de maneira consciente, sem nenhuma postura de superioridade e, geralmente, sem utilizar-se de subterfúgios.

Podemos afirmar que, a partir da clareza demonstrada pelos discursos desse bloco, o instrumento da auto-avaliação pode contribuir significativamente para a interação plena de alunos e professores, num processo verdadeiramente reforçador das aprendizagens e das experiências vivenciadas. Nesse sentido, concordamos que a principal contribuição da auto-avaliação é “[...] confirmar a validade de um empreendimento. É constatar se a estratégia escolhida, na busca de algo, funcionou, era a mais adequada à situação e compensou, isto é, satisfaz nossas expectativas." (SANT'ANNA, 2005, p. 17).

\section{CONSIDERAÇÕES FINAIS}

Nosso interesse em publicar este artigo sobre uma pesquisa realizada, fruto de uma prática de auto-avaliação numa disciplina ministrada em um curso de pós-graduação, é contribuir para que mais profissionais docentes superem os argumentos de que seus alunos não são capazes de atribuir-se, de forma consciente e crítica, um conceito auto-avaliativo, uma nota referente ao seu desempenho de aprendizagem. É, também, contribuir para que esses docentes possam confiar aos alunos a possibilidade de conduzir o próprio desempenho, conscientizando-se dos fracassos e êxitos alcançados.

Podemos afirmar que, a partir da explicitação e condução de um processo de auto-avaliação que envolve várias etapas bem definidas e claras, os alunos desenvolvem um sentimento de responsabilidade pessoal e de co-responsabilidade social: além de apreciar de forma 
crítica e consciente seu desempenho e sua aprendizagem, são capazes de perceber-se como parte de um grupo, de identificar nos sujeitos que fazem parte do grupo suas competências, saberes, posturas, comportamentos, dentre outros aspectos, e de comparar tudo isso com suas próprias potencialidades, apreciando os esforços seus e de seus parceiros, identificando se houve eficácia do processo (em nível pessoal e do grupo).

Podemos perceber, ainda, que os alunos demonstram um significativo desejo de melhorar sua aprendizagem quando se sentem incentivados a revelar suas percepções sobre o seu desempenho e o do grupo, numa espécie de co-responsabilidade no processo de avaliação, aferindo conceitos bem próximos de seu real desempenho. Quando não atingem pleno domínio dessa capacidade, ainda assim buscam uma forma de justificar-se, mesmo que para tanto utilizem determinados subterfúgios, em algumas situações.

Finalmente, podemos concluir que a auto-avaliação, conduzida de forma que o aluno tenha uma visão clara de onde pretende chegar, expressada livremente e centrada na cooperação, visto buscar a aprendizagem significativa de todo um grupo, constitui-se em um instrumento privilegiado para uma avaliação autêntica. Ela contribui para que os professores acreditem mais em seus alunos, assim como favorece a dinamização dos programas de especialização, notadamente na concretização de um processo avaliativo que respeite as diferenças individuais e contribua para o desenvolvimento pleno de todos os envolvidos.

\section{REFERÊNCIAS}

BLOOM, B. et al. Manual de avaliação formativa e somativa do aprendizado escolar. São Paulo: Pioneira, 1983.

CARDOSO, S. H. B. Discurso e ensino. 2. ed. Belo Horizonte: Autêntica, 2005.

FERREIRA, L. Retratos da avaliação: conflitos, desvirtuamentos e caminhos para a superação. Porto Alegre: Mediação, 2002.

INSTITUTO NACIONAL DE ESTUDOS E PESQUISAS EDUCACIONAIS ANISIO TEIXEIRA - INEP. Sistema Nacional de Avaliação da Educação Superior, Roteiro de Auto-Avaliação Institucional: orientações gerais. Brasília, 2004. 
HOFFMANN, J. Avaliação mediadora: uma prática em construção da préescola à universidade. 14. ed. Porto Alegre: Mediação, 1998.

LUKE, A. Análise do discurso numa perspectiva crítica. In: HYPOLITO, Á. M.; GANDIM, L. A. (Org.). Educação em tempos incertos. 2. ed. Belo Horizonte: Autêntica, 2003. p. 93-110.

MAINGUENEAU, D. Análise de textos de comunicação. São Paulo: Cortez, 2001.

MASETTO, M. Auto-avaliação em cursos de pós-graduação: teoria e prática. Campinas: Papirus, 2004.

ORLANDI, E. P. Análise de discurso: princípios e procedimento. 6. ed. Campinas: Pontes, 2005.

. Discurso e texto: formulação e circulação dos sentidos. Campinas: Pontes, 2001.

SANT'ANNA, I. M. Por que avaliar? Como avaliar? Critérios e instrumentos. 3. ed. Petrópolis: Vozes, 1995.

Encaminhado em: 20/08/06

Aceito em: 30/08/06 